becomes more popular, the use of an accurate definition of cortical scarring is essential. T J BEATTIE
Renal Unit J R MACKENZIE Department of Radiology, Royal Hospital for Sick Children,

Glasgow G3 $8 S f$

1 Jakobsson B, Berg U, Svensson L. Renal scarring after acute pyelonephritis. Arch Dis Child 1994, 70: $111-5$.

2 Tappin DM, Murphy AV, Mocan $\mathrm{H}$, et al. A prospective study of children with first acute symptomatic E-coli urinary tract infection: early 99M Tc DMSA appearances. Acta Paediatr Scand 1989; 78: 923-9.

Drs Fakobsson, Berg, and Svensson comment: Drs Beattie and MacKenzie raise an important question. In our paper we have used the same criteria for renal scarring as used by Rushton et al. ${ }^{1}$ The results of both studies are similar. We consider a defect, still present on a DMSA scan after two years as a thinning or flattening of the renal parenchyma, and on the same site as the original insult, to be a sign of irreversible renal damage. Moreover, a scar situated on the front or on the back of the kidney will not disturb the cortical outline when only a posterior projection is used, as was the case in our study. It is difficult to believe that proximal tubular cells not functioning after two years from the insult will return to normal function. The anecdotal experience described by $\mathrm{Dr}$ Beattie and $\mathrm{Dr}$ MacKenzie may be explained by hypertrophy of remaining healthy proximal tubular cells resulting in an improvement of DMSA uptake, obscuring the original defect.

As the use of DMSA scan is becoming more popular, one will find signs of permanent renal damage in children after acute pyelonephritis more frequently than previously when intravenous urography was used. We will not know for some time how we should interpret many of these defects seen on a DMSA scan but not on intravenous urography in terms of risk for later complications. The term 'renal scarring' is well defined as it appears on intravenous urography and the term 'parenchymal reduction' is used for kidneys with signs of parenchymal thinning only. Maybe we should proceed in the same manner with regard to findings on DMSA scan, reserving the term renal scarring for kidneys with reduced DMSA uptake without preservation of the cortical outline, and parenchymal reduction or thinning for those with reduced uptake with preservation of the cortical outline. In both cases, however, the kidney is permanently damaged.

1 Rushton HG, Majd M, Jantausch B, Wiedermann $\mathrm{BL}$, Belman AB. Renal scarring following reflux and nonreflux pyelonephritis in children: evaluation with $99 \mathrm{~m}_{\text {technetium-dimercaptosuc- }}$ cinic acid scintigraphy. $\mathcal{f}$ Urol 1992; 147: 1327-32.

\section{Acute hepatitis due to brucella in a 2 year old child}

EDITOR,-Liver involvement is frequent in acute and chronic brucellosis. Usually an increase in transaminase values and a mild hepatosplenomegaly occur, sometimes an acute hepatitis develops, but it is rarely the only clinical manifestation of the infection. ${ }^{1}$ We report a case where hepatitis was the only manifestation of acute brucellosis.

The patient, a 2 year old boy from Sicily, with an unremarkable history, was found by chance to have hepatosplenomegaly and high transaminase values (aspartate aminotransferase (AST) $220 \mathrm{IU} / 1$; alanine aminotransferase (ALT) $570 \mathrm{IU} / \mathrm{l}$ ). Because of the persistence of this clinical picture, he was admitted to our department one month later. Clinical examination showed good general condition, apyrexia, hepatosplenomegaly, inguinal and laterocervical microadenia, and normal neuropsychic development. Laboratory tests showed haemoglobin $122 \mathrm{~g} / \mathrm{l}$, platelet count $155 \times 10^{9} / 1$, white cell count $5.3 \times 10^{9} /$, erythrocyte sedimentation rate $5 \mathrm{~mm} /$ hour, AST 793 IU/l, ALT 1184 IU/l, alkaline phosphatase $805 \mathrm{IU} / \mathrm{l}, \gamma$-glutamyltransferase 72 IU/l, and lactate dehydrogenase 1314 IU/l. Abdominal ultrasonography showed moderate hepatosplenomegaly, without any structural or morphological changes. Common causes of viral, metabolic and immunological liver damage were excluded by specific assays.
Because of a further increase in transaminase values (AST 1065 IU/l, ALT 1552 IU/l), liver biopsy was performed. The biopsy specimen showed a picture of a specific reactive hepatitis with microgranulomas. The possible causes of liver granulomatosis were investigated. ${ }^{2}$ Mantoux intradermal reaction and serological test for chlamydia, mycoplasma, and rickettsia were negative. The Wright reaction was positive (Brucella abortus 1:640, Brucella melitensis 1:160). The diagnosis was confirmed on a liver biopsy specimen by indirect immunofluorescence, using specific monoclonal antibody ISS $/ 32 .^{3}$

A more accurate study of the patient's history showed intake of homemade fresh cheese prepared by local shepherds.

After recommended treatment, ${ }^{4}$ liver function tests returned to within the normal range and the titre measured by the Wright reaction decreased ( $B$ abortus 1:80, $B$ melitensis 1:20).

This case shows that acute hepatitis may represent the first and the only manifestation of brucellosis. Brucellosis must be considered in the differential diagnosis of hepatitis, especially in patients coming from endemic regions.

G LOSURDO
A TIMITILLI
L TASSO
C CARLI
F CIUCHINI
R ADONE†
R GIACCHINO
Department of Infectious Diseases and * Department
of Pathology,
G Gaslini Children's Hospital,
Largo G Gaslini 5,
16147 Genoa, Italy
tVeterinary Department,
Istituto Superiore di Sanita, Rome

1 Titone L, Scarlata F, Giordano S. Epatic involvement of brucellosis. Giomale Malattie Infettive e Parassitarie 1987; 39: 46-8.

2 Harrington PT, Gutitèrrez JJ, Ramirez-Ronda $\mathrm{CH}$, Quinones-Soto R, Bermudez RH, Chaffey J. Granulomatous hepatitis. Rev Infect Dis 1982; 4: 638-55.

3 Adone R, Ciuchini S, Pistoia C, Marcon G, Piccininno G. Protective activity to murine experimental brucellosis conferred by monoclonal antibody ISS/32 anti-B abortus. Fo
of Veterinary Medicine 1991; 38: 397-400.

4 Lubani MM Medicine 1991; 38: 397-400. center therapeutic study of 1100 children with brucellosis. Pediatr Infect Dis f 1989; 8: 75-8. 